\title{
On Nano Generalized Pre Regular Closed Sets in Nano Topological Spaces
}

\author{
C.R Parvathy ${ }^{1}$, S. Praveena ${ }^{2}$ \\ ${ }^{1}$ Assistant Professor, Department of Mathematics, PSGR Krishnammal College for Women, Coimbatore, \\ Tamilnadu, India. \\ ${ }^{2}$ Assistant Professor, Department of Mathematics, Dr.SNS Rajalakshmi College of Arts and Science, \\ Coimbatore, Tamilnadu, India.
}

\begin{abstract}
In this paper a class of sets called Nano generalized pre regular closed sets is introduced and its properties are studied. Further the notation of Nano pre regular $T_{1 / 2}$ space and Nano generalized pre regular continuity are discussed.
\end{abstract}

Keywords: Nano Generalized Pre Regular Closed sets, Nano Pre Regular $T_{1 / 2}$ spaces, Ngpr continuous,

Ngpr irresolute.

\section{Introduction}

In 1970, Levine [6] introduced the concept of generalized closed sets as a generalization of closed sets in topological spaces. Later on N. Palaniappan [7] studied the concept of regular generalized closed set in a topological space. Maki et al [1] introduced the concepts of generalized pre closed sets and pre generalized closed sets in an analogous manner. In 1977, Y. Gnanambal [10] have introduce the concept of generalized pre regular closed sets in topological spaces. In 2011, Sharmistha Bhattacharya [9] have introduced the notation of generalized regular closed sets in topological space. The notation of Nano topology was introduced by Lellis Thivagar [4], which was defined in terms of approximations and boundary region of a subset of an universe using an equivalence relation on it and also defined Nano closed sets, Nano interior and Nano closure. Moreover in this paper we defined Nano pre regular $T_{1 / 2}$ spaces as the spaces in which every Nano generalized pre regular closed sets is Nano pre closed. We also introduce the notation of Nano generalized pre regular continuity and study its properties.

\section{Preliminaries}

Definition 2.1 [5] Let $U$ be a non-empty finite set of objects called the universe and $\mathrm{R}$ be an equivalence relation on $\mathrm{U}$ named as the indiscernibility relation. Then $\mathrm{U}$ is divided into disjoint equivalence classes. Elements belonging to the same equivalence class are said to be indiscernible with one another. The pair $(U, R)$ is said to be the approximation space. Let $\mathrm{X} \subseteq \mathrm{U}$.

1. The lower approximation of $X$ with respect to $R$ is the set of all objects, which can be for certain classified as $\mathrm{X}$ with respect to $\mathrm{R}$ and its is denoted by $\mathrm{L}_{\mathrm{R}}(\mathrm{X})$.

$$
\mathrm{L}_{\mathrm{R}}(\mathrm{X})=\bigcup_{x \in U}\{\mathrm{R}(\mathrm{x}): \mathrm{R}(\mathrm{x}) \subseteq \mathrm{X}\}
$$

where $R(X)$ denotes the equivalence class determined by $x \in U$.

2. The upper approximation of $\mathrm{X}$ with respect to $\mathrm{R}$ is the set of all objects, which can be possibly classified as $\mathrm{X}$ with respect to $\mathrm{R}$ and it is denoted by $\mathrm{U}_{\mathrm{R}}(\mathrm{X})$.

$$
\mathrm{U}_{\mathrm{R}}(\mathrm{X})=\bigcup_{x \in U}\{\mathrm{R}(\mathrm{x}): \mathrm{R}(\mathrm{x}) \cap \mathrm{X}=\phi\} .
$$

3. The boundary region of $\mathrm{X}$ with respect to $\mathrm{R}$ is the set of all objects, which can be possibly classified neither as $\mathrm{X}$ nor as not $\mathrm{X}$ with respect to $\mathrm{R}$ and it is denoted by $\mathrm{B}_{\mathrm{R}}(\mathrm{X})$.

$$
\mathrm{B}_{\mathrm{R}}(\mathrm{X})=\mathrm{U}_{\mathrm{R}}(\mathrm{X})-\mathrm{L}_{\mathrm{R}}(\mathrm{X}) \text {. }
$$

Property 2.2 [5] If $(\mathrm{U}, \mathrm{R})$ is an approximation space and $X, Y \subseteq U$, then

1. $L_{R}(X) \subseteq X \subseteq U_{R}(X)$.

2. $L_{R}(\phi)=U_{R}(X)=\phi \& L_{R}(U)=U_{R}(U)=U$.

3. $U_{R}(X \cup Y)=U_{R}(X) \cup U_{R}(Y)$.

4. $U_{R}(X \cap Y) \subseteq U_{R}(X) \cap U_{R}(Y)$.

5. $L_{R}(X \cup Y) \supseteq L_{R}(X) \cup L_{R}(Y)$. 
6. $L_{R}(X \cap Y) \subseteq L_{R}(X) \cap L_{R}(Y)$.

7. $L_{R}(X) \subseteq L_{R}(Y) \& U_{R}(X) \subseteq U_{R}(Y)$ whenever $X \subseteq Y$.

8. $U_{R}\left(X^{C}\right)=\left[L_{R}(X)\right]^{C} \& L_{R}\left(X^{C}\right)=\left[U_{R}(X)\right]^{C}$.

9. $U_{R} U_{R}(X)=L_{R} U_{R}(X)=U_{R}(X)$.

10. $L_{R} L_{R}(X)=U_{R} L_{R}(X)=L_{R}(X)$.

Definition 2.3 [4] Let $\mathrm{U}$ be the universe, $\mathrm{R}$ be an equivalence relation on $\mathrm{U}$ and $\tau_{R}(X)=\left\{\mathrm{U}, \phi, \mathrm{L}_{\mathrm{R}}(\mathrm{X})\right.$, $\left.\mathrm{U}_{\mathrm{R}}(\mathrm{X}), \mathrm{B}_{\mathrm{R}}(\mathrm{X})\right\}$ where $\mathrm{X} \subseteq \mathrm{U}$. Then by property $\tau_{R}(X)$ satisfies the following axioms:

1. $\mathrm{U}$ and $\phi \in \tau_{R}(X)$

2. The union of the elements of any subcollection of $\tau_{R}(X)$ is in $\tau_{R}(X)$

3. The intersection of the elements of any finite subcollection of $\tau_{R}(X)$ is in $\tau_{R}(X)$.

Then $\tau_{R}(X)$ is a topology on $\mathrm{U}$ called the Nano topology on $\mathrm{U}$ with respect to $\mathrm{X}$. $\left(\mathrm{U}, \tau_{R}(X)\right)$ as the Nano topological space. The elements of $\tau_{R}(X)$ are called as Nano-open sets and complement of Nano open sets is called Nano closed.

Definition 2.4 [4] If $\left(\mathrm{U}, \tau_{R}(X)\right)$ is a Nano topological space with respect to $\mathrm{X}$ where $\mathrm{X} \subseteq \mathrm{U}$ and if $\mathrm{A} \subseteq \mathrm{U}$, then the Nano interior of A is defined as the union of all Nano-open subsets contained in A and it is denoted by $\operatorname{NInt}(A)$. That is, NInt(A) is the largest Nano-open subset of A. The Nano closure of A is defined as the intersection of all Nano closed sets containing $\mathrm{A}$ and it is denoted by $\mathrm{NCl}(\mathrm{A}) . \mathrm{NCl}(\mathrm{A})$ is the smallest $\mathrm{Nano}$ closed set containing A.

Definition 2.5 [8] Let $\left(\mathrm{U}, \tau_{R}(X)\right)$ be a Nano topological space and $\mathrm{A} \subseteq \mathrm{U}$. Then $\mathrm{A}$ is said to be

1. Nano Pre-open if $\mathrm{A} \subseteq \mathrm{NInt}(\mathrm{NCl}(\mathrm{A}))$.

2. Nano Pre-closed if $\mathrm{NCl}(\mathrm{NInt}(\mathrm{A})) \subseteq \mathrm{A}$.

3. Nano Regular open if $\mathrm{A} \subseteq \mathrm{NInt}(\mathrm{NCl}(\mathrm{A}))$.

4. Nano Regular closed if $\mathrm{NCl}(\mathrm{NInt}(\mathrm{A})) \subseteq \mathrm{A}$.

Definition 2.6 [3] Let $\left(\mathrm{U}, \tau_{R}(X)\right)$ be a Nano topological space. A subset $\mathrm{A}$ of $\left(\mathrm{U}, \tau_{R}(X)\right)$ is called Nano generalized closed set (briefly $\mathrm{Ng}$-closed) if $\mathrm{NCl}(\mathrm{A}) \subseteq \mathrm{V}$ where $\mathrm{A} \subseteq \mathrm{V}$ and $\mathrm{V}$ is $\mathrm{Nano}$ open.

Definition 2.7 [2] If $\left(\mathrm{U}, \tau_{R}(X)\right)$ is a Nano topological space with respect to $\mathrm{X}$ where $\mathrm{X} \subseteq \mathrm{U}$ and if $\mathrm{A} \subseteq \mathrm{U}$, then the Nano pre interior of $A$ is defined as the union of all Nano pre open subsets of A contained in $A$ and it is denoted by NpInt(A). NpInt(A) is the largest Nano pre open subset of A. The Nano pre closure of A is defined as the intersection of all Nano pre closed sets containing A and it is denoted by $\operatorname{Npcl}(\mathrm{A})$. That is, $\operatorname{Npcl}(\mathrm{A})$ is the smallest Nano pre closed set containing A.

Definition 2.8 [2] A subset A of ( $\left.\mathrm{U}, \tau_{R}(X)\right)$ is called Nano generalized pre closed set (briefly Ngp-closed) if $\operatorname{Npcl}(\mathrm{A}) \subseteq \mathrm{V}$ whenever $\mathrm{A} \subseteq \mathrm{V}$ and $\mathrm{V}$ is Nano open in $\left(\mathrm{U}, \tau_{R}(X)\right)$.

Definition 2.9 [5] Let $\left(\mathrm{U}, \tau_{R}(X)\right)$ and $\left(\mathrm{V}, \tau_{R}{ }^{\prime}(Y)\right)$ be a Nano topological spaces. Then a mapping $f:\left(U, \tau_{R}(X)\right) \rightarrow\left(V, \tau_{R}{ }^{\prime}(Y)\right)$ is Nano continuous on $\mathrm{U}$ if the inverse image of every Nano - open set in $\mathrm{V}$ is Nano - open in $\mathrm{U}$.

III. Nano Generalized Pre Regular Closed Sets And Nano Pre Regular $T_{1 / 2}$ Spaces Throughout this paper $\left(\mathrm{U}, \tau_{R}(X)\right)$ is a Nano topological space with respect to $\mathrm{X}$ where $X \subseteq U, \mathrm{R}$ is an equivalence relation on $U$. Then $U / R$ denotes the family of equivalence classes of $U$ by $R$. In this section, we define and study forms of Nano generalized closed sets and Nano pre regular $T_{1 / 2}$ spaces.

Definition 3.1 A subset A of $\left(\mathrm{U}, \tau_{R}(X)\right)$ is called Nano Generalized pre regular closed set (briefly $\mathrm{Ngpr}$ closed) if $\operatorname{Npcl}(A) \subseteq A$ whenever $A \subseteq V$ and $\mathrm{V}$ is Nano regular open in $\mathrm{U}$.

Definition 3.2 A set $A \subseteq U$ is called Nano generalized pre regular open if and only if its complement is Nano generalized pre regular closed.

Example 3.3 Let $U=\{a, b, c, d\}$ with $U / R=\{\{a\},\{c\},\{b, d\}\}$ and $X=\{a, b\}$. Then $\tau_{R}(X)=\{U, \Phi,\{a\}$, $\{a, b, d\},\{b, d\}\}$ which are open sets. The Nano generalized pre closed sets $=\{U, \Phi,\{b\},\{c\},\{d\},\{a, c\},\{b, c\}$, 
$\{c, d\},\{a, b, c\},\{a, c, d\},\{b, c, d\}\}$. The Nano regular closed sets $=\{U, \Phi,\{b, c, d\},\{a, c\},\{c\}\}$. The Nano generalized pre regular closed sets $=\{\mathrm{U}, \Phi,\{\mathrm{a}, \mathrm{c}, \mathrm{d}\},\{\mathrm{a}, \mathrm{b}, \mathrm{d}\},\{\mathrm{a}, \mathrm{b}, \mathrm{c}\},\{\mathrm{b}, \mathrm{d}\},\{\mathrm{a}, \mathrm{d}\},\{\mathrm{a}, \mathrm{b}\},\{\mathrm{d}\},\{\mathrm{b}\},\{\mathrm{a}\}\}$.

Remark 3.4 $\operatorname{Npcl}(U-A)=U-N p \operatorname{int}(A)$

Theorem 3.5 Every Nano regular generalized closed set is Nano generalized pre regular closed.

Proof. Let $A \subseteq U$ be a nano regular generalized closed. Let $A \subseteq V$ and $\mathrm{V}$ is nano regular open. Then $\operatorname{Ncl}(A) \subseteq V$ since A is Nrg - closed. Since every Nano closed set is Nano pre closed, $\operatorname{Npcl}(A) \subseteq \operatorname{Ncl}(A)$. Therefore, $\operatorname{Npcl}(A) \subseteq V$. Hence A is Ngpr - closed.

Theorem 3.6 Let A be Ngpr - closed in $\left(\mathrm{U}, \tau_{R}(X)\right)$. Then Npcl(A)-A does not contain any non - empty Nano regular closed set.

Proof. Let $\mathrm{F}$ be a Nano regular closed set such that $F \subseteq \operatorname{Npcl}(A)-A$. Then $F \subseteq U-A$ implies $A \subseteq U-F$. A is Ngpr - closed and U-F is Nano regular open. Therefore $N p c l \subseteq U-F$. It is $F \subseteq U-\operatorname{Npcl}(A)$. Hence $F \subseteq \operatorname{Npcl}(A) \cap(U-\operatorname{Npcl}(A))=\phi$. This shows $F=\phi$.

Theorem 3.7 If A is Ngpr - closed and $A \subseteq B \subseteq \operatorname{Npcl}(A)$ then B is Ngpr - closed.

Proof. Let $B \subseteq V$ where $\mathrm{V}$ is Nano regular open. Then $A \subseteq B$ implies $A \subseteq V$. Since A is Ngpr - closed $\operatorname{Npcl}(A) \subseteq V . \quad B \subseteq \operatorname{Npcl}(A)$ implies $\operatorname{Npcl}(B) \subseteq \operatorname{Npcl}(A)$. Thus $\operatorname{Npcl}(B) \subseteq U$ and shows that B is Ngpr - closed.

Theorem 3.8 $A \subseteq U$ is Ngpr - open if and only if $F \subseteq N p \operatorname{int}(A)$ whenever F is Nano regular closed and $F \subseteq A$.

Proof. Necessity: Let A be Ngpr-open. Let $\mathrm{F}$ be Nano regular closed and $F \subseteq A$. Then $U-A \subseteq U-F$ where U-F is Nano regular open. Ngpr - closedness of U-F implies $\operatorname{Npcl}(U-A) \subseteq U-F$. By remark 3.4, $U-N p \operatorname{int}(A) \subseteq U-F$. It is $F \subseteq N p i n(A)$. Sufficiency: Suppose $\mathrm{F}$ is Nano regular closed and $F \subseteq A$ implies $F \subseteq N p \operatorname{int}(A)$. Let $U-A \subseteq V$ where $\mathrm{V}$ is Nano regular open. Then $U-V \subseteq A$ where $\mathrm{U}-\mathrm{V}$ is Nano regular closed. By hypothesis, $U-V \subseteq N p \operatorname{int}(A)$. It is $U-N p \operatorname{int}(A) \subseteq V$. By remark 3.4, $\operatorname{Npcl}(U-A) \subseteq V$. This implies U-A is Ngpr-closed and A is Ngpr-open.

Preposition 3.9 Let $\mathrm{Npo}(\mathrm{U})$ be Nano closed under finite intersections. If A is Ngpr open and B is Ngpr open then $\mathrm{A} \cap \mathrm{B}$ is Ngpr-open.

Proof. Let $U-(A \cap B)=(U-A) \cup(U-B) \subseteq F$. Where $\mathrm{F}$ is Nano regular open. Then $U-A \subseteq F$ and $U-B \subseteq F$. Since $\mathrm{A}$ and $\mathrm{B}$ are Ngpr - open, $\operatorname{Npcl}(U-A) \subseteq F$ and $\operatorname{Npcl}(U-B) \subseteq F$. By hypothesis, $\quad \operatorname{Npcl}((U-A) \cup(U-B)) \subseteq \operatorname{Npcl}(U-A)-\operatorname{Npcl}(U-B) \subseteq F . \quad$ It $\quad$ is $\operatorname{Npcl}(U-(A \cap B)) \subseteq F$. This shows that $A \cap B$ is Ngpr - open.

\section{Theorem 3.10}

1. $\quad \operatorname{NPO}\left(\tau_{R}(X)\right) \subset N G P R O\left(\tau_{R}(X)\right)$.

2. A space $\left(U, \tau_{R}(X)\right)$ is Nano pre regular $T_{1 / 2}$ if and only if $\operatorname{NPO}\left(\tau_{R}(X)\right)=\operatorname{NGPRO}\left(\tau_{R}(X)\right)$.

Proof.

1. Let A Nano open. Then U-A is Nano pre closed and so Ngpr - closed. This implies A is Ngpr - open. Hence $\operatorname{NPO}\left(\tau_{R}(X)\right) \subset N G P R O\left(\tau_{R}(X)\right)$.

2. Necessity : Let $\left(U, \tau_{R}(X)\right)$ be Nano pre regular $T_{1 / 2}$. Let $N G P R O\left(\tau_{R}(X)\right)$. Then $\mathrm{U}-\mathrm{A}$ is Ngpr - closed. By hypothesis U-A is Nano pre closed and this $A \in N P O\left(\tau_{R}(X)\right)$. Hence $\operatorname{NGPRO}\left(\tau_{R}(X)\right)=\operatorname{NPO}\left(\tau_{R}(X)\right)$. Sufficiency : Let $N P O\left(\tau_{R}(X)\right)=\operatorname{NGPRO}\left(\tau_{R}(X)\right)$. Let A be $\mathrm{Ngpr}-$ closed. Then U-A is Ngpr - open. Hence $U-A \in N P O\left(\tau_{R}(X)\right)$. Thus A is Nano pre closed there by implying $\left(U, \tau_{R}(X)\right)$ is nano pre regular $T_{1 / 2}$. 


\section{NGPR Continuous And NGPR Irresolute}

Throughout this paper $\mathrm{U}$ and $\mathrm{V}$ are nonempty, finite universe. $X \subseteq U, Y \subseteq V \& Z \subseteq W ; U / R$, $V / R^{\prime} \& W / R^{\prime \prime}$ denotes the family of equivalence classes by equivalence relations $\mathrm{R}, \mathrm{R}$, , R" respectively on $\mathrm{U}, \mathrm{V} \& \mathrm{~W} .\left(U, \tau_{R}(X)\right),\left(V, \tau_{R^{\prime}}(Y)\right),\left(W, \tau_{R^{\prime \prime}}(Z)\right)$ are the nano topological spaces with respect to $\mathrm{X}, \mathrm{Y}, \mathrm{Z}$ respectively.

Definition: 4.1 A function $f:\left(U, \tau_{R}(X)\right) \rightarrow\left(V, \tau_{R^{\prime \prime}}(Y)\right)$ is called Ngpr continuous if $f^{-1}(V)$ is Ngpr closed in $\left(U, \tau_{R}(X)\right)$ for every Nano closed set of $\left(V, \tau_{R^{\prime \prime}}(Y)\right)$.

Example: 4.2 Let $\mathrm{U}=\{\mathrm{a}, \mathrm{b}, \mathrm{c}, \mathrm{d}\}, \tau_{R}(X)=\{\mathrm{U}, \Phi,\{\mathrm{a}\},\{\mathrm{a}, \mathrm{b}, \mathrm{d}\},\{\mathrm{b}, \mathrm{d}\}\}$ and $\mathrm{V}=\{\mathrm{a}, \mathrm{b}, \mathrm{c}\}$, $\tau_{R^{\prime}}(X)=\{U, \phi,\{a\},\{b, c\}\}$. Define $f:\left(U, \tau_{R}(X)\right) \rightarrow\left(V, \tau_{R^{\prime \prime}}(Y)\right)$ by $\mathrm{f}(\mathrm{a})=\mathrm{a}, \mathrm{f}(\mathrm{c})=\mathrm{b}$ and $\mathrm{f}(\mathrm{d})=\mathrm{c}$. Since every subset of $\left(U, \tau_{R}(X)\right)$ is Ngpr - closed, $f:\left(U, \tau_{R}(X)\right) \rightarrow\left(V, \tau_{R^{\prime \prime}}(Y)\right)$ is $\mathrm{Ngpr}$ Continuous.

Definition: 4.3 A function $f:\left(U, \tau_{R}(X)\right) \rightarrow\left(V, \tau_{R^{\prime \prime}}(Y)\right)$ is called Ngpr irresolute if $f^{-1}(V)$ is Ngpr closed in $\left(U, \tau_{R}(X)\right)$ for every Ngpr closed set $\mathrm{V}$ of $\left(V, \tau_{R^{n}}(Y)\right)$.

Example: 4.4 Let $\mathrm{U}=\{\mathrm{a}, \mathrm{b}, \mathrm{c}, \mathrm{d}\}, \tau_{R}(X)=\{\mathrm{U}, \Phi,\{\mathrm{a}\},\{\mathrm{a}, \mathrm{b}, \mathrm{d}\},\{\mathrm{b}, \mathrm{d}\}\}$ and $\mathrm{V}=\{\mathrm{a}, \mathrm{b}, \mathrm{c}\}$, $\tau_{R^{\prime}}(Y)=\{U, \phi,\{a\},\{a, b, d\},\{b, d\}\}$. Define $f:\left(U, \tau_{R}(X)\right) \rightarrow\left(V, \tau_{R^{\prime \prime}}(Y)\right)$ by $\mathrm{f}(\mathrm{a})=\mathrm{b}, \mathrm{f}(\mathrm{b})=\mathrm{c}$ and $\mathrm{f}(\mathrm{c})=\mathrm{d}$ and $\mathrm{f}(\mathrm{d})=\mathrm{a}$. Then the inverse image of every Ngpr closed set is Ngpr closed under f. Hence $\mathrm{f}$ is Ngpr irresolute.

Theorem: 4.5 Let $f:\left(U, \tau_{R}(X)\right) \rightarrow\left(V, \tau_{R^{\prime \prime}}(Y)\right)$ be Nano regular irresolute and Nano pre closed. Then for every Ngpr - closed set of A of $f:\left(U, \tau_{R}(X)\right) \rightarrow\left(V, \tau_{R^{\prime \prime}}(Y)\right)$. $\mathrm{f}(\mathrm{A})$ is $\operatorname{Ngpr}$ closed in $\left(V, \tau_{R^{\prime \prime}}(Y)\right)$.

Proof. Let A be Ngpr - closed in $\left(U, \tau_{R}(X)\right)$. Let $f(A) \subseteq V^{\prime}$ where $V^{\prime}$ is Nano regular open in $\mathrm{V}$. Then $A \subseteq f^{-1}\left(V^{\prime}\right)$. Since $\mathrm{f}$ is Nano regular irresolute and $\mathrm{A}$ is $\operatorname{Ngpr}-\operatorname{closed}, \operatorname{Npcl}(A) \subseteq f^{-1}(V)$. That is , $f\left(\operatorname{Npcl}(A) \subseteq V^{\prime}\right.$. Now $\operatorname{Npcl}(f(A)) \subseteq \operatorname{Npcl}(f(\operatorname{Npcl}(A)))=f(\operatorname{Npcl}(A)) \subseteq V^{\prime}$. Since $\mathrm{f}$ is Nano pre closed. Hence $\mathrm{f}(\mathrm{A})$ is Ngpr - closed in $\left(V, \tau_{R^{\prime \prime}}(Y)\right)$.

Theorem: 4.6 Let $f:\left(U, \tau_{R}(X)\right) \rightarrow\left(V, \tau_{R^{\prime \prime}}(Y)\right)$ and $g:\left(V, \tau_{R^{\prime \prime}}(Y)\right) \rightarrow\left(W, \tau_{R^{\prime \prime}}(Z)\right)$ be any two functions. Then

1. $g \circ f$ is Ngpr - Continuous, if $\mathrm{g}$ is Nano Continuous and $\mathrm{f}$ is $\mathrm{Ngpr}-$ continuous.

2. $g \circ f$ is $\mathrm{Ngpr}$ - irresolute, if $\mathrm{g}$ is Nano irresolute and $\mathrm{f}$ is $\mathrm{Ngpr}$ - irresolute.

3. $g \circ f$ is Ngpr Continuous, if $\mathrm{g}$ is Ngpr continuous and $\mathrm{f}$ is Ngpr irresolute.

Proof. 1. Let $V^{\prime}$ be closed in $\left(W, \tau_{R^{\prime}}(Z)\right)$. Then $g^{-1}\left(V^{\prime}\right)$ is closed in $\left(V, \tau_{R^{n}}(Y)\right)$. Since $g$ is Nano continuous. Ngpr continuous of $\mathrm{f}$ implies $f^{-1}\left[g^{-1}\left(V^{\prime}\right)\right]$ is $\operatorname{Ngpr}-\operatorname{closed} \operatorname{in}\left(U, \tau_{R}(X)\right)$. That is $(g \circ f)^{-1}\left(V^{\prime}\right)$ is Ngpr - closed in $\left(U, \tau_{R}(X)\right)$. Hence $(g \circ f)$ is Ngpr - continuous. 2. Let $V^{\prime}$ be Nano closed in $\left(W, \tau_{R^{\prime \prime}}(Z)\right)$. Since $\mathrm{g}$ is $\mathrm{Ngpr}-$ irresolute, $g^{-1}\left(V^{\prime}\right)$ is $\mathrm{Ngpr}$ closed in $\left(V, \tau_{R^{\prime \prime}}(Y)\right)$. As $\mathrm{f}$ is Ngpr irresolute $f^{-1}\left[g^{-1}\left(V^{\prime}\right)\right]=(g \circ f)^{-1}\left(V^{\prime}\right)$ is Ngpr closed in $\left(U, \tau_{R}(X)\right)$. Therefore $g \circ f$ is Ngpr irresolute. 3. Let $V^{\prime}$ be closed in $\left(W, \tau_{R^{\prime}}(Z)\right)$. Since $g$ is Ngpr - continuous. $g^{-1}\left(V^{\prime}\right)$ is ngpr closed in $\left(V, \tau_{R^{\prime \prime}}(Y)\right)$. As $\mathrm{f}$ is Ngpr irresolute $f^{-1}\left[g^{-1}\left(V^{\prime}\right)=(g \circ f)^{-1}\left(V^{\prime}\right)\right.$ is Ngpr - closed in $\left(U, \tau_{R}(X)\right)$. $g \circ f$ is Ngpr Continuous. 


\section{References}

[1] H. Maki ,J. Umehara and T. Noiri, “Every Topological space is pre- $T_{1 / 2}$ ”, Mem. Fac. Sci. Kochi Univ. Ser.A . math., 17(1996), 33-42.

[2] K. Bhuvaneswari and K. Mythili Gnanapriya, "Nano Generalized pre Closed sets and Nano Pre Generalized Closed Sets in Nano topological spaces", International Journal of Innovative Research in Science, Engineering And Technology. Volume 3 Issue 10, Oct 2014.

[3] K. Bhuvaneswari and K. Mythili Gnanapriya, "Nano Generalized Closed sets in Nano topological spaces", International Journal of Scientific and Research Publications, Volume 4, Issue 5, May 2014

[4] M. Lellis Thivagar and Carmel Richard "Note on Nano topological spaces" - (communicated).

[5] M. Lellis Thivagar and Carmel Richard, "On Nano Continuity”, Mathematical Theory and Modeling, Vol- 3, No. 7, 2013.

[6] Levine N. (1970), "Generalized closed sets in Topology”, Rend. Circ. Math. Palermo, 19, 89-96.

[7] N. Palaniappan and K. Chandarasekhara Rao, “Regular generalized closed sets", Kyungpook math.J, 33(1993), 211-219.

[8] Sulochana Devi P, Bhuvaneswari K, “On nano regular generalized and nano generalized regular closed sets", IJETT 2014, 13(8), 386-390.

[9] Sharmistha Bhattacharya (Halder), "On generalized regular closed sets", Int. J. Contemp. Math. Sci., 6(2011), $145-152$.

[10] Y. Gnanambal, “On generalized pre regular closed sets in topological spaces”, Indian J. Pure. Appl. Math., 28(3)(1997), 351-360.

[11] Y. Gnanambal and K. Balachandran, "On GPR - Continuous Functions in Topological Spaces”, Indian Journal of Pure and Applied Mathematics, 30(6): 581 - 593, June - 1999. 